\title{
Megaeventos e Turismo no Rio de Janeiro: um olhar sobre o Planejamento Estratégico e a promoção da imagem da cidade
}

Megaevents and Tourism in Rio de Janeiro: a look at a Strategic Planning and the promotion of the image of the city

Megaeventos y Turismo en Río de Janeiro: una mirada sobre la Planificación Estratégica y la promoción de la imagen de la ciudad

Ana Maria Vieira Fernandes

Pontifícia Universidade Católica de Campinas (PUC-

DOI: https://doi.org/10.18472/cvt.19n1.2019.1532

Redalyc: http://www.redalyc.org/articulo.oa?

Campinas), Brasil

$\mathrm{id}=115459473003$

ana.mfernandes@gmail.com

Recepção: 31 Janeiro 2018

Aprovação: 26 Novembro 2018

\section{Resumo:}

A cidade do Rio de Janeiro orientou sua gestão para políticas estratégicas que promoveram renovações urbanas em seu espaço desde a década de 1990, o que a tornou palco de megaeventos, como a Copa do Mundo (2014) e os Jogos Olímpicos (2016). Perante a discussão sobre quais são as questões que emergem após a realização dos megaeventos na cidade, este artigo objetivou analisar como o Rio orientou a sua governança pública a partir dos Planos Estratégicos e quais foram as principais ações previstas nestes para o desenvolvimento do turismo e para a promoção da sua imagem a fim de posicionar-se de forma competitiva internacionalmente. As metodologias adotadas foram: pesquisas bibliográfica, documental e de campo (nas intervenções urbanas promovidas como espaços de consumo e lazer), e entrevistas com gestores públicos e moradores afetados. Aponta-se que nenhuma ação estratégica visou o desenvolvimento qualitativo do turismo participativo; somente focou no aumento do fluxo de turistas. As intervenções elitizaram os espaços públicos e atenderam a uma pequena parcela, evidenciando que tais políticas visaram a promoção da cidade e não o bem-estar social, em um processo claro de gentrificação.

PalaVras-chaVe: Planejamento Estratégico, Megaeventos, Turismo, Rio de Janeiro.

\section{Abstract:}

The city of Rio de Janeiro guided its management to strategic policies that have promoted urban renewal in its space since the 1990s, which has made it the scene of mega-events such as the World Cup (2014) and the Olympic Games (2016). In the face of discussing the issues that emerge after the megaevents in this city, this article aimed to analyze how Rio governed its public governance based on the Strategic Plans and what were the main actions envisaged in them the development of tourism and the promotion of its image in order to position itself in an international competitive manner. The methodologies were: bibliographic, documentary and field research (in urban interventions promoted as spaces of consumption and leisure), and interviews with public managers and affected residents. It is pointed out that no strategic action aimed at the qualitative development of participatory tourism; only focused on increasing the flow of tourists. The interventions elicited public spaces and attended to a small portion, showing that these policies aimed at promoting the city and not social welfare, in a clear process of gentrification.

KEYWORDS: Strategic Planning, Mega events, Tourism, Rio de Janeiro.

\section{Resumen:}

La ciudad de Río de Janeiro ha orientado su gestión hacia políticas estratégicas que han promovido renovaciones urbanas desde la década de 1990, lo que la convirtió en escenario de megaeventos como la Copa del Mundo (2014) y los Juegos Olímpicos (2016). En vista de discutir cuáles son las cuestiones que emergen después de la realización de los megaeventos, ese artículo objetivó analizar de qué forma el Rio orientó su gobernanza a partir de los Planes Estratégicos y cuáles fueron sus acciones para el desarrollo del turismo y la promoción de su imagen a fin de posicionarse de forma competitiva internacionalmente. Las metodologías fueron: investigaciones bibliográficas, documental y de campo (en las intervenciones promovidas como espacios de consumo y ocio), y entrevistas con gestores públicos y vecinos afectados. Se apunta que ninguna acción tuvo como objetivo el desarrollo cualitativo del turismo participativo; sólo se centró en el aumento del flujo de turistas. Las intervenciones elitizaron los espacios públicos y atendieron a una pequeña parcela, evidenciando que tales políticas buscaran la promoción de la ciudad y no al bienestar social, en un proceso claro de gentrificación. 
Palabras ClaVe: Planes Estratégicos, Megaeventos, Turismo, Rio de Janeiro.

\section{INTRODUÇÃO}

Cada vez mais incorporados às agendas políticas de cidades contemporâneas, os megaeventos vêm sendo cobiçados pelos gestores públicos como uma estratégia de posicionamento competitivo no mercado econômico em nível mundial.

Sendo o turismo uma atividade com viés econômico capaz de gerar empregos e renda para a destinação onde se desenvolve, esta torna-se uma variável de competitividade essencial para muitas destinações. A competitividade de um destino turístico pode ser caracterizada pela “[...] capacidade que um destino turístico tem para concorrer com outros destinos do mundo, gerando um nível de renda superior à média e mantendo essa situação a longo prazo" (VIGNATI, 2008, p. 113).

Nesse sentido, a corrida pela competitividade em nível mundial objetiva aumentar a capacidade de atratividade das cidades, tornando-as objetos de desejo que encabeçam os rankings de destinos mais visitados do mundo. O desejo de tornar-se competitiva pode ser materializado pelos megaeventos, capazes de captar investimentos que possibilitem a efetivação de algumas políticas públicas, como projetos de mobilidade urbana e infraestrutura, instalação de equipamentos culturais e esportivos e infraestrutura turística, alimentando parcerias público-privadas responsáveis por intervenções urbanas no espaço a partir de uma gestão estratégica, além da promoção da imagem dessas cidades na mídia internacional para o fomento do turismo (FERNANDES, 2017).

Barcelona (Espanha) e Sidney (Austrália) são exemplos emblemáticos de cidades que se posicionaram competitivamente e que foram inseridas no "mapa turístico mundial" por sediarem as Olimpíadas dos anos de 1992 e 2000, respectivamente. A renovação urbana de ambas e a promoção de suas imagens em nível mundial fizeram com que se consolidassem dentro do mercado turístico, recebendo grande fluxo de visitantes até os dias atuais. As Olimpíadas de Sidney trouxeram para a Austrália um adicional de 1,7 milhão de visitantes (MTUR, 2011), assim como Barcelona que consolidou-se como um dos destinos mais visitados da Europa (BARCELONA TURISME, 2015). No Brasil essa lógica foi materializada na cidade do Rio de Janeiro, por meio de uma governança orientada por Planos Estratégicos que focaram em sediar na última década alguns dos mais importantes megaeventos esportivos, como a Copa do Mundo de Futebol (2014) e os Jogos Olímpicos (2016), que recebeu 6 milhões de turistas estrangeiros (MINISTÉRIO DO TURISMO, 2016).

Assim, as cidades-sede de megaeventos são espetacularizadas pelas obras de renovação urbana que as transformam em espaços de lazer e de consumo voltadas para uma demanda solvente (VAINER, 2002). Esse novo "modelo" de cidade é difundido pelo marketing urbano, previsto como uma das estratégias de ação dos Planos, fazendo com que a promoção da imagem dessas cidades renovadas seja a legitimação de suas ideologias socioespaciais.

É o caso da cidade do Rio de Janeiro. Buscando posicionar-se competitivamente no cenário global, orientou a sua governança para os Planos Estratégicos e aproveitou a visibilidade alcançada pelos Jogos para promover a sua imagem por meio das intervenções urbanas sofridas, como a renovação da antiga área portuária que transformou a Praça Mauá a partir da derrubada do Elevado da Perimetral e da instalação de equipamentos culturais, como o emblemático Museu do Amanhã, transformando essa área em um novo cartão-postal carioca.

Perante a discussão sobre quais foram as questões emergidas após a realização dos megaeventos na cidade do Rio de Janeiro, com enfoque nos Jogos Rio 2016, este artigo objetivou analisar de que forma a cidade carioca orientou a sua governança pública a partir dos Planos Estratégicos e quais foram as principais ações previstas nestes para o desenvolvimento do turismo e para a promoção da sua imagem, a fim de posicionarse de forma competitiva internacionalmente. Ainda foi analisado de que forma as iniciativas estratégicas 
para o desenvolvimento do turismo foram efetivadas e se elas podem ser consideradas oportunidades para o desenvolvimento econômico e social do Rio, ou se somente reforçaram as desigualdades existentes na cidade.

\section{PROCEDIMENTOS METODOLÓGICOS}

Este artigo, baseado em tese de Doutorado, foi desenvolvido a partir de pesquisas bibliográficas e documentais sobre o tema e também pesquisas de campo na cidade do Rio de Janeiro. Tais pesquisas foram realizadas durante o primeiro semestre de 2016 e também durante o período de realização dos Jogos, sobretudo nos principais locais que sofreram intervenções, como a Praça Mauá e o Parque Olímpico. Ainda foram realizadas entrevistas semiestruturadas com gestores públicos municipais e representantes de associações de moradores de bairros afetados pelas intervenções urbanas.

O presente artigo estrutura-se a partir de dois eixos principais, além de uma introdução, dos procedimentos metodológicos e dos apontamentos finais. O primeiro eixo apresenta os Planos Estratégicos da cidade do Rio de Janeiro e as iniciativas ligadas diretamente ao desenvolvimento turístico e à promoção da imagem da cidade. Já o segundo eixo apresenta os dados coletados em pesquisa de campo, analisando se as ações estratégicas previstas para o fomento do turismo e para a promoção da imagem do Rio em âmbito internacional foram efetivadas.

\section{OS PLANOS ESTRATÉGICOS DO RIO DE JANEIRO}

A cidade do Rio de Janeiro vem orientando a sua governança pública a partir do empreendedorismo urbano e do planejamento estratégico (HARVEY, 1996; VAINER, 2002), o que conduziu ações orientadas para fortalecê-la como uma cidade global a partir de megaeventos, que reforçaram a sua imagem como um destino turístico internacional.

De acordo com Vainer (2002, p. 76), o planejamento estratégico “[...] deve ser adotado pelos governos locais em razão de estarem as cidades submetidas às mesmas condições e desafios que as empresas”. As políticas desse tipo de planejamento têm como prioridade a inserção das cidades nos mercados globais de produção e consumo. Assim, "o empresariamento urbano implica, contudo, em algum grau de competição interurbano" (HARVEY, 1996, p. 56).

A governança das cidades, a partir de uma postura empresarial, exige que os gestores públicos adotem Planos Estratégicos compostos por ações que enfatizem a competitividade entre as cidades. "Produtividade, competitividade e subordinação dos fins à lógica do mercado” (VAINER, 2002, p. 85) são as premissas desse estilo de governança. Nesse sentido, esse tipo de gestão urbana transforma os seus projetos em produtos e serviços para que as cidades se tornem atraentes para os seus investidores (VAINER, 2002). Segundo Borja \& Forn (1996, p. 34), a venda da cidade é baseada na venda dos insumos valorizados pelo capital transnacional: "[...] espaços para convenções, parques industriais e tecnológicos, oficinas de informação e assessoramento a investidores e empresários, torres de comunicação e comércio, segurança...”.

A governança da cidade do Rio orientada pelo planejamento estratégico teve início a partir da década de 1990, quando as políticas neoliberais em nível municipal tornaram-se evidentes a partir do acordo firmado no primeiro ano de gestão do prefeito César Maia [1], em 1993, entre a Prefeitura Municipal do Rio de Janeiro, a Associação Comercial (ACRJ) e a Federação das Indústrias (Firjan) para a elaboração e promoção do Plano Estratégico da Cidade do Rio de Janeiro (PECRJ) (VAINER, 2002).

Para garantir o financiamento dos projetos que seriam elaborados pelo Plano, foi criado, em 1994, o Consórcio Mantenedor do PECRJ, nomeado oficialmente como Plano Estratégico da Cidade do Rio de Janeiro (PECRJ), conhecido pelo seu slogan "Rio Sempre Rio". O objetivo do consórcio, composto por 46 empresas, associações, organizações empresariais e por agentes do setor público, foi o de elaborar um Plano 
Estratégico para o município visando à promoção e ao desenvolvimento local, bem como à retomada de sua imagem como cidade turística (FISCHER; GUANAIS, 1999; VAINER, 2000). Ao reforçarem que o Rio era o primeiro município do hemisfério sul a ter um Plano Estratégico, evidenciava-se a sua intenção competitiva (CARLOS, 2013; OLIVEIRA, 2008; PIRES, 2010).

Ainda em 1994 foi instaurado o Conselho da Cidade que, de acordo com Vainer (2000), reunia mais de 300 membros entre diversos agentes sociais, como poder público, empresários, universidades, jornalistas e presença popular, esta representada por poucos membros. Todavia, o papel do Conselho era o de homologar as decisões tomadas pelo Conselho Executivo em um processo pouco democrático: "a função do Conselho da Cidade é meramente simbólica” (VAINER, 2000, p. 109). Assim, o Plano Estratégico acabou por substituir o Plano Diretor da Cidade (1992), o que “[...] empreendeu uma radical mudança nos rumos do planejamento urbano da cidade preparando-a para grandes eventos internacionais” (CARLOS, 2013, p. 32).

Apesar de sua contribuição pelo seu caráter democrático, os gestores públicos acreditavam que o Plano Diretor possuía certa rigidez em relação à administração do município, caracterizado como "imobilizante" e "estático" (CARLOS, 2013; PIRES, 2010). Tal substituição foi uma perda em termos de inclusão da população nas tomadas de decisão, uma vez que os Planos Estratégicos são norteados por coalizões públicoprivadas que defendem os interesses hegemônicos.

As próximas gestões públicas (Luiz Paulo Conde - 1997 a 2001 e, novamente, César Maia - 2001 a 2009) deram continuidade às medidas previstas no Rio Sempre Rio. Já na gestão do prefeito Eduardo Paes (2009 2013 e 2013 a 2016), um novo Plano Estratégico foi publicado, "O Rio mais integrado e competitivo (2009 - 2012)”, deixando clara a sua opção pela continuidade da governança empresarial. Foi com essa mentalidade que o Rio foi sede dos Jogos Pan-Americanos (2007), evento que revelou-se como um ensaio para a inserção da cidade na rota internacional dos megaeventos esportivos. Desse modo:

O Plano Estratégico da cidade, pouco a pouco, foi preparando a sua estrutura urbana e financeira para receber grandes eventos, encarados pelos sucessivos gestores como inquestionáveis grandes oportunidades capazes de gerar legados importantes para sua infraestrutura urbana com ganhos para seu contexto social (CARLOS, 2013, p. 39).

A partir da elaboração de um diagnóstico referente às dez principais áreas de resultado da governança (saúde; educação; emprego e renda; infraestrutura urbana; ordem pública; meio ambiente; transportes; cultura, esporte e lazer; assistência social e finanças públicas), este Plano traçou 37 iniciativas estratégicas (PLANO ESTRATÉGICO DA CIDADE DO RIO DE JANEIRO, 2009). No que diz respeito à projeção internacional da imagem da cidade, foco deste trabalho, os objetivos das iniciativas explicitam que as intervenções urbanas planejadas foram orientadas de modo a posicionar competitivamente a imagem do Rio como um importante centro político e cultural, conforme consta em seu objetivo: "tornar a cidade do Rio de Janeiro o melhor lugar para se viver e trabalhar no hemisfério sul” (PLANO ESTRATÉGICO DA CIDADE DO RIO DE JANEIRO, 2009, p. 11).

O Quadro 1 destaca as iniciativas estratégicas visando às obras de renovação da cidade para o seu posicionamento internacional e a atração de turistas estrangeiros. 
QUADRO 1

Estratégias visando ao posicionamento internacional do Rio de Janeiro

\begin{tabular}{|c|c|c|}
\hline $\begin{array}{l}\text { Área de } \\
\text { Resultado }\end{array}$ & Iniciativa Estratégica & Metas \\
\hline \multirow[t]{2}{*}{$\begin{array}{l}\text { Emprego e } \\
\text { Renda }\end{array}$} & $\begin{array}{l}\text { Rio Capital do Turismo: } \\
\text { embora a cidade já seja } \\
\text { consolidada no } \\
\text { mercado turístico, o } \\
\text { número de visitantes } \\
\text { vem decrescendo } \\
\text { devido ao aumento da } \\
\text { insegurança, da } \\
\text { ausência de política de } \\
\text { promoção da imagem } \\
\text { da cidade e da } \\
\text { infraestrutura turistica } \\
\text { obsoleta. }\end{array}$ & $\begin{array}{l}\text { Criação de uma } \\
\text { política de } \\
\text { promoção da } \\
\text { cidade; expansão } \\
\text { da rede hoteleira; } \\
\text { sinalização } \\
\text { turística; aumento } \\
\text { do número de } \\
\text { turistas e geração } \\
\text { de empregos no } \\
\text { setor. }\end{array}$ \\
\hline & $\begin{array}{l}\text { Rio Capital da Moda e } \\
\text { Design: cidade como } \\
\text { referência no setor } \\
\text { devido à inspiração em } \\
\text { suas belezas naturais e } \\
\text { no "jeito do carioca". }\end{array}$ & $\begin{array}{l}\text { Programas de } \\
\text { capacitaçăo; } \\
\text { renovação urbana } \\
\text { (Marina da Glória } \\
\text { como espaço de } \\
\text { eventos ligados à } \\
\text { moda); atração de } \\
\text { empresas } \\
\text { internacionais do } \\
\text { setor e aumento da } \\
\text { visibilidade do Rio } \\
\text { no exterior. } \\
\end{array}$ \\
\hline $\begin{array}{l}\text { Infraestrutura } \\
\text { Urbana }\end{array}$ & $\begin{array}{l}\text { Porto Maravilha: } \\
\text { renovação urbana da } \\
\text { área portuária: } \\
\text { oportunidade de } \\
\text { valorização patrimonial } \\
\text { da cidade. Espaço } \\
\text { degradado e sem uso } \\
\text { que pode se } \\
\text { transformar em grande } \\
\text { potencial turístico, } \\
\text { econômico e social. }\end{array}$ & $\begin{array}{l}\text { Renovação da área } \\
\text { com a melhoria na } \\
\text { condição de vida } \\
\text { local; atração de } \\
\text { novos moradores e } \\
\text { empresas; e } \\
\text { incremento de } \\
\text { atividades } \\
\text { culturais e } \\
\text { turísticas. }\end{array}$ \\
\hline Transporte & $\begin{array}{l}\text { TransCarioca e } \\
\text { Transoeste: com a } \\
\text { expansão da cidade } \\
\text { para a Barra da Tijuca, } \\
\text { o transporte público } \\
\text { que liga partes da } \\
\text { cidade a essa região } \\
\text { ficou precário, lento e } \\
\text { oneroso. }\end{array}$ & $\begin{array}{l}\text { Criação de } \\
\text { corredores de } \\
\text { ônibus expressos, } \\
\text { em faixa dedicada, } \\
\text { ligando partes da } \\
\text { cidade à Barra da } \\
\text { Tijuca. }\end{array}$ \\
\hline \multirow[t]{2}{*}{$\begin{array}{l}\text { Cultura, } \\
\text { Esporte e } \\
\text { Lazer }\end{array}$} & $\begin{array}{l}\text { Expansão de quadras e } \\
\text { vilas olimpicas: a } \\
\text { cidade apresenta } \\
\text { carência de } \\
\text { equipamentos } \\
\text { desportivos. }\end{array}$ & $\begin{array}{l}\text { Ampliação de } \\
\text { espaços para } \\
\text { prática esportiva: } \\
\text { construção de } \\
\text { quadras esportivas } \\
\text { com acessibilidade } \\
\text { para portadores de } \\
\text { necessidades } \\
\text { especiais, nas } \\
\text { escolas municipais } \\
\text { e áreas públicas. }\end{array}$ \\
\hline & $\begin{array}{l}\text { Cultura na rua: } \\
\text { incorporar a prática } \\
\text { cultural no cotidiano do } \\
\text { carioca. }\end{array}$ & \begin{tabular}{|l} 
Calendário de \\
eventos culturais \\
gratuitos; \\
programações \\
diversas visando \\
ocupar diversas \\
regiôes da cidade.
\end{tabular} \\
\hline
\end{tabular}


Ana Maria Vieira Fernandes. Megaeventos e Turismo no Rio de Janeiro: um olhar sobre o Planejament...

Plano Estratégico da Cidade do Rio de Janeiro, 2009. Organizado pelo autor, 2016.

Dando continuidade a esse modelo de gestão, o prefeito Eduardo Paes publicou uma nova versão do Plano Estratégico da Cidade: "Rio pós-2016 - O Rio mais integrado e competitivo (2013 - 2016)" (PLANO ESTRATÉGICO DA CIDADE DO RIO DE JANEIRO, 2013). O novo plano deu enfoque ao Rio Olímpico e ressaltou o sucesso do plano anterior. As suas iniciativas estratégicas, agora 58, também foram distribuídas segundo às dez áreas de resultado da governança já mencionadas. O Quadro 2 apresenta os projetos relacionados ao legado olímpico que constam no Plano. 
QUADRO 2

Iniciativas estratégicas relacionadas diretamente ao legado olímpico

\begin{tabular}{|c|c|c|}
\hline $\begin{array}{l}\text { Area de } \\
\text { Resultado }\end{array}$ & Iniciativa Estratégica & Metas \\
\hline Educação & $\begin{array}{l}\text { Rio Criança Global: } \\
\text { proporcionar } \\
\text { oportunidades futuras. }\end{array}$ & $\begin{array}{l}\text { Estender o ensino } \\
\text { da língua inglesa } \\
\text { para os alunos do } \\
10 \text { ao } 90 \text { ano de } \\
\text { todas as escolas } \\
\text { municipais da } \\
\text { cidade. }\end{array}$ \\
\hline Transportes & $\begin{array}{l}\text { Modernização da frota } \\
\text { de ônibus (BRT); } \\
\text { TransOeste; } \\
\text { TransCarioca; } \\
\text { TransOlimpica; } \\
\text { TransBrasil e VLT do } \\
\text { Centro }\end{array}$ & $\begin{array}{l}\text { Melhorar a } \\
\text { qualidade do } \\
\text { transporte público } \\
\text { e da mobilidade } \\
\text { urbana. }\end{array}$ \\
\hline \multirow[t]{2}{*}{$\begin{array}{l}\text { Habitação e } \\
\text { Urbanização }\end{array}$} & $\begin{array}{l}\text { Porto Maravilha: Idem } \\
\text { infraestrutura urbana } \\
\text { do Quadro } 1 .\end{array}$ & $\begin{array}{l}\text { Idem } \\
\text { infraestrutura } \\
\text { urbana do Quadro } \\
1 .\end{array}$ \\
\hline & $\begin{array}{l}\text { Parque Olimpico: } \\
\text { legado ambiental, } \\
\text { arquitetônico, cultural e } \\
\text { econômico sustentável } \\
\text { em benefício do } \\
\text { ambiente urbano e da } \\
\text { qualidade de vida dos } \\
\text { cidadâos. }\end{array}$ & $\begin{array}{l}\text { Legado esportivo } \\
\text { para a cidade a } \\
\text { partir da criação } \\
\text { do Centro } \\
\text { Olímpico de } \\
\text { Treinamento. }\end{array}$ \\
\hline \multirow[t]{2}{*}{$\begin{array}{l}\text { Ordem Pública e } \\
\text { Conservação }\end{array}$} & $\begin{array}{l}\text { Rio em Ordem: atuação } \\
\text { da Guarda Municipal e } \\
\text { dos órgấos de } \\
\text { fiscalização e controle } \\
\text { urbano e promover o } \\
\text { ordenamento do espaço } \\
\text { público. }\end{array}$ & $\begin{array}{l}\text { Restabelecimento } \\
\text { da Ordem Pública } \\
\text { gerando um } \\
\text { ambiente mais } \\
\text { seguro para o } \\
\text { morador e turistas. }\end{array}$ \\
\hline & $\begin{array}{l}\text { Rio Acessivel: } \\
\text { renovação de } \\
\text { pavimentos, remoção } \\
\text { de obstáculos e } \\
\text { implantação de } \\
\text { rampas, implantação } \\
\text { de piso tátil, faixas } \\
\text { lisas para cadeirantes e } \\
\text { correção de meio-fio. }\end{array}$ & $\begin{array}{l}\text { Tornar o Rio } \\
\text { referência em } \\
\text { acessibilidade: } \\
\text { logradourose } \\
\text { transporte } \\
\text { adaptados para } \\
\text { deficientes; e } \\
\text { novas obras } \\
\text { realizadas nos } \\
\text { padrões de } \\
\text { acessibilidade. }\end{array}$ \\
\hline \multirow[t]{2}{*}{$\begin{array}{l}\text { Meio Ambiente e } \\
\text { Sustentabilidade }\end{array}$} & $\begin{array}{l}\text { Expansão do } \\
\text { Saneamento: } \\
\text { universalização do } \\
\text { saneamento } \\
\text { envolvendo o } \\
\text { esgotamento sanitário, } \\
\text { drenageme } \\
\text { pavimentação nas } \\
\text { áreas mais deficitárias. }\end{array}$ & $\begin{array}{l}\text { Melhoria da saúde } \\
\text { pública e da } \\
\text { qualidade de vida } \\
\text { e redução de } \\
\text { despejo de esgotos } \\
\text { sem tratamento } \\
\text { nos rios. }\end{array}$ \\
\hline & $\begin{array}{l}\text { Qualidade de Águas } \\
\text { Urbanas: despoluiçã̃o } \\
\text { das baias de } \\
\text { Guanabara, Sepetiba e } \\
\text { lagoas de Jacarepaguá } \\
\text { e Barra, e praias } \\
\text { oceânicas. }\end{array}$ & $\begin{array}{l}\text { Ampliação da rede } \\
\text { coletora de } \\
\text { esgotos, novas } \\
\text { ETEs e medidas } \\
\text { estruturantes para } \\
\text { controle da } \\
\text { poluição difusa. }\end{array}$ \\
\hline $\begin{array}{l}\text { Desenvolvimento } \\
\text { Econômico }\end{array}$ & $\begin{array}{l}\text { Rio Capital do Turismo: } \\
\text { Idem Emprego e Renda } \\
\text { do Quadro 1. }\end{array}$ & $\begin{array}{l}\text { Idem Emprego e } \\
\text { Renda do Quadro } \\
1 .\end{array}$ \\
\hline $\begin{array}{l}\text { Desenvolvimento } \\
\text { Social }\end{array}$ & $\begin{array}{l}\text { Rio em Forma } \\
\text { Olimpica: implantação } \\
\text { de núcleos em } \\
\text { comunidades que } \\
\text { ofereçam atividades } \\
\text { esportivas, culturais, } \\
\text { sociais, éticas e de } \\
\text { saúde. }\end{array}$ & $\begin{array}{l}\text { Melhor } \\
\text { aproveitamento do } \\
\text { tempo ocioso dos } \\
\text { jovens em áreas } \\
\text { carentes; } \\
\text { estabelecimento de } \\
\text { uma cultura de } \\
\text { hábitos saudáveis. }\end{array}$ \\
\hline
\end{tabular}


Plano Estratégico da Prefeitura do Rio de Janeiro (2013 - 2016). Organizado pelo autor, 2016.

Para melhor compreensão de como foram organizados esses projetos, o então presidente da Autoridade Pública Olímpica (APO) ${ }^{[2]}$ afirmou em entrevista realizada durante trabalho de campo que as intervenções urbanas foram divididas em dois eixos: a Matriz de Responsabilidade e o Plano de Políticas Públicas. A Matriz de Responsabilidade ficou a cargo do Comitê Rio 2016 e abrangia as intervençóes exclusivas para os Jogos, como o Parque Olímpico e sua infraestrutura, o centro internacional de mídia e a Vila dos Atletas.

Já o Plano de Políticas Públicas foi de responsabilidade da gestão pública municipal e dizia respeito à infraestrutura da cidade para receber as competições. O entrevistado afirmou que esses investimentos se caracterizam pela ampliação ou antecipação de políticas públicas que gerariam um legado, tendo em vista o desenvolvimento urbano. Algumas intervenções desse Plano são os projetos apresentados no Quadro 2. É importante destacar que esses projetos contribuem direta e indiretamente para o fomento turístico de uma destinação. Contudo, este artigo dá enfoque às iniciativas estratégicas ligadas diretamente ao turismo, como "Porto Maravilha" e "Rio Capital do Turismo" [3].

No que diz respeito ao projeto "Porto Maravilha", uma das intervenções mais expressivas, sua meta foi consolidar a nova região portuária como um local de fomento à cultura. Hoje, tal área se apresenta como um novo centro cultural, de lazer e consumo. A partir desse projeto, o Rio consolidou novos atrativos turísticos por meio de uma nova tematização que vai além das praias, do carnaval e do Réveillon, e que engloba e dá destaque à cultura em seu novo "mapa turístico". A Praça Mauá tornou-se o símbolo da renovação da região portuária, uma vez que o viaduto Elevado da Perimetral, que marcava essa paisagem, foi implodido e o local ganhou dois novos equipamentos culturais: o Museu de Arte do Rio (MAR) e o Museu do Amanhã (Figura 1), além da abertura do Boulevard Olímpico, responsáveis por transformar significativamente a paisagem dessa área, dando-lhe novos simbolismos, usos e dinâmicas e transformando-a em um cartão-postal. A nova região portuária ainda teve um protagonismo nos Jogos, pois foi o principal live site ${ }^{[4]}$ do megaevento.

De acordo com o guia de turismo e morador da região portuária entrevistado[5], o turismo ali vem crescendo cada vez mais devido às novas instalações culturais, o que não ocorria antes da renovação, pois, segundo ele, o local era afastado, perigoso e repleto de atividades ilícitas.

Já a área de resultado "Desenvolvimento Econômico" evidencia a relação entre os megaeventos e a atividade turística por meio da iniciativa estratégica "Rio Capital do Turismo". De acordo com o Plano,

Apesar de continuar sendo o principal destino de lazer e a principal porta de entrada de turistas internacionais no país, o Rio precisa investir na melhoria da sua infraestrutura e nos seus equipamentos com vistas a aumentar o fluxo de turistas na cidade, que não vem crescendo significativamente nos últimos anos (PLANO ESTRATÉGICO DA CIDADE DO RIO DE JANEIRO, 2013, p. 95).

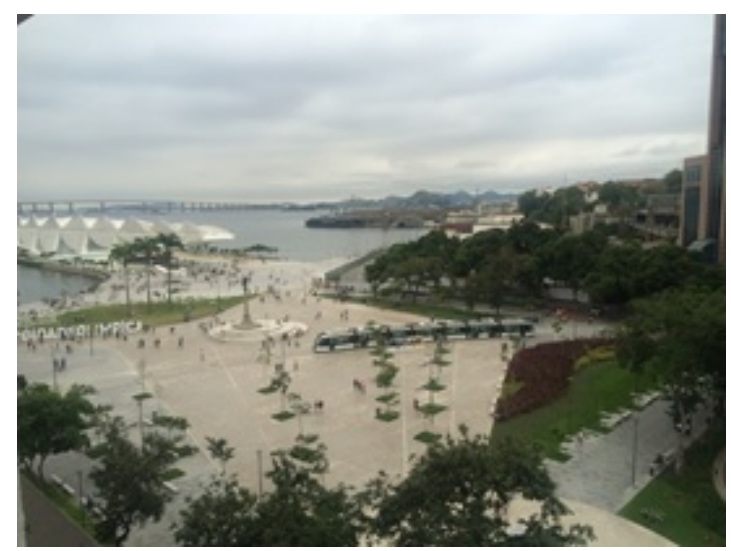

FIGURA 1

Praça Mauá renovada e Museu do Amanhã

Do autor, 2016 
Portanto, aproveitar a oportunidade dos megaeventos para realizar intervenções urbanas e promover internacionalmente a imagem do Rio "repaginado", a fim de atrair um fluxo maior de turistas foi uma das prioridades desse governo. As ações que orientam essa iniciativa estratégica - "Rio Capital do Turismo" são estruturadas em quatro pilares principais, que serão apresentados no item subsequente.

\section{O TURISMO E A PROMOÇÃO DA CIDADE OLÍMPICA}

Dentro do marco analítico do planejamento estratégico, as políticas de promoção da imagem das cidades possuem uma função essencial. É a partir do marketing urbano, ou seja, da promoção dos projetos urbanísticos realizados que é feita a “[...] tentativa de construir um imaginário físico e social de cidades adequadas para esses propósitos competitivos” (HARVEY, 1996, p. 60). É a divulgação e a promoção dos espaços renovados que irão atrair os consumidores reais e potenciais e legitimar o novo projeto de cidade.

O Rio também buscou utilizar a imagem de cidade renovada como estratégia para se promover, como explicam Sánchez, Guterman e Laiber (2015, p. 4):

Foi construída a ideia de que chegou "a vez do Rio", um "momento único" para a cidade e seus cidadãos a partir de 2009. A partir da imagem cristalizada do "Rio do turismo, do lazer e de belezas incomparáveis", o projeto da cidade olímpica busca sua atualização e associação a novos valores, produzindo a imagem de uma nova cidade que além de bela é também segura para investimentos, para os cidadãos e para o turista.

Nesse sentido, os Planos Estratégicos da cidade apresentaram iniciativas para efetivar esse posicionamento e atrair um fluxo maior de turistas. Como já mencionado, a iniciativa estratégica "Rio Capital do Turismo" foi estruturada em quatro pilares visando à melhoria do ambiente da cidade para essa atividade. São eles: i) investimentos em infraestrutura turística, melhoria na hospitalidade e sinalização turística; ii) campanhas de promoção da imagem da cidade; iii) definição do posicionamento estratégico do turismo na cidade e iv) ampliação da oferta de leitos de hotéis (PLANO ESTRATÉGICO DA CIDADE DO RIO DE JANEIRO, 2013).

No rol de estratégias de promoção da imagem da cidade, como prevê o segundo pilar e foco deste artigo, a Praça Mauá, que abriga dois novos equipamentos culturais - Museu de Arte do Rio (MAR) e Museu do Amanhã -, foi o local mais utilizado como imagem da renovação urbana. É mister ressaltar que o Museu do Amanhã é uma iniciativa da Prefeitura do Rio concebida e realizada em conjunto com a Fundação Roberto Marinho, ligada ao grupo Globo, grande corporação midiática[6], o que evidencia as coalizões entre gestão municipal e iniciativa privada, típicas do Planejamento Estratégico. O papel das mídias, ao estimular e incentivar os novos usos e consumos neste novo espaço simbólico, é determinante para engendrar o projeto de cidade renovada e, por isso, foi atribuído ao novo equipamento cultural tamanha visibilidade, tornandoo um espaço simbólico da cidade.

Essa imagem de renovação urbana foi utilizada das mais diversas formas, desde veículos promocionais voltados ao turismo, como a Revista "visit.rio" (Figura 2) que ilustra o emblemático Museu do Amanhã na capa, até em um jogo de tabuleiro, "Banco Imobiliário - Cidade Olímpica", distribuído nas escolas municipais pelo então prefeito Eduardo Paes (Figura 3). No tabuleiro do jogo são destacadas algumas obras previstas nos Planos Estratégicos, como novamente o Museu do Amanhã, a TransCarioca, os BRTs, bem como os atrativos turísticos consolidados, como o Cristo Redentor e o Pão de Açúcar (SÁNCHEZ; GUTERMAN; LAIBER, 2015; VAINER, 2000), em uma clara legitimação política referente ao legado turístico dos Jogos para a cidade. 


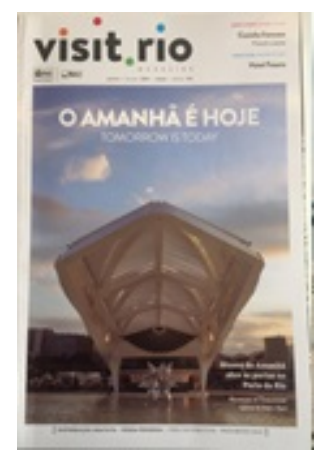

FIGURA 2

Capa Visit Rio

visit.rio Magazine, 2016

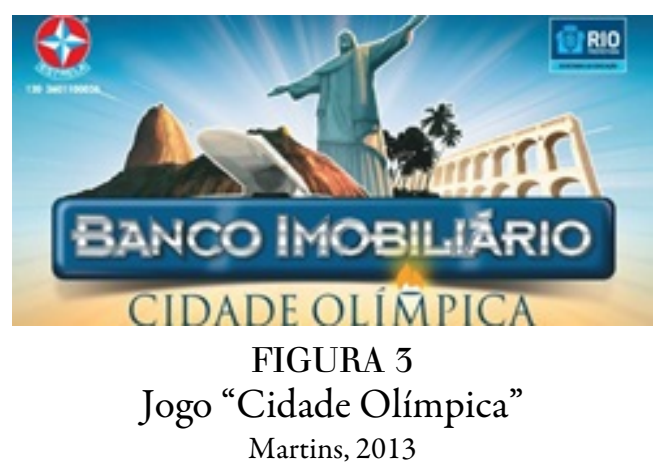

O site oficial Rio 2016 ainda promoveu a cidade a partir de representações "[...] entrelaçadas aos aspectos pinçados das identidades culturais cariocas, como o samba e sua 'tradicional' ginga” (SÁNCHEZ; GUTERMAN; LAIBER, 2015, p. 5) e deixou de lado imagens contraditórias, como a pobreza e as favelas, revelando a intencionalidade de que a cidade é para turistas e investidores, e não para seus moradores. Nesse sentido:

As representações produzidas para a "venda da cidade do Rio" podem ser interpretadas como peças de afirmação da hegemonia local, pelas quais o poder de classe das elites é legitimado e oferecido ao consumo do estrangeiro, onde a cultura popular ressurge pacificada, as misturas sociais são toleradas e as diferenças domesticadas, para valorizá-las com traços da urbanidade carioca. Diversidade e harmonia num sítio de grande beleza paisagística produzem a imagem-síntese que remete ao mito de origem da "Cidade Maravilhosa", que busca consensos ao mesmo tempo em que dilui conflitos (SÁNCHEZ; GUTERMAN; LAIBER, 2015, p. 5).

Outra estratégia de divulgação foi o concurso "Rio em Cartaz", promovido pelo Instituto Rio Patrimônio da Humanidade. A quarta edição (2015) promoveu a renovação urbana pelo tema "Centro para todos" incorporando, uma vez mais, os novos projetos de renovação como o Museu do Amanhã e o VLT na paisagem do centro. A Figura 4 apresenta o cartaz vencedor da última edição.

Durante o período dos Jogos, o city marketing ainda contribuiu para uma maior difusão da imagem da cidade a partir das transmissões das emissoras internacionais de televisão, onde a paisagem carioca ficou evidente, sobretudo a imagem que marcou o encerramento das Olimpíadas no Maracanã: o Cristo Redentor iluminado nas cores verde e amarelo de "braços abertos sobre a Guanabara", como cantava Tom Jobim em seu Samba do Avião. 


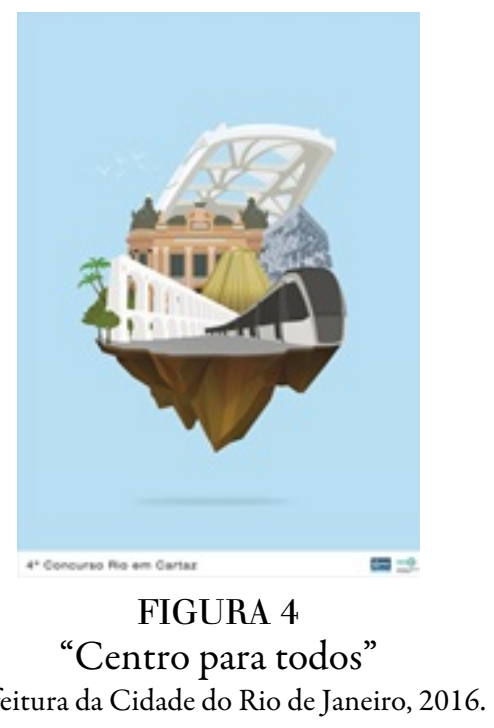

Os próprios turistas também colaboraram para a promoção da imagem da cidade quando a fotografavam e a divulgavam em suas redes sociais. Segundo pesquisa realizada pelo Ministério do Turismo, o Rio foi o destino nacional mais divulgado nas redes sociais em 2016, com mais de 300 mil publicações de fotos. Segundo a pesquisa, a maioria das fotos foi feita nos locais renovados, como a Praça Mauá (VIEIRA, 2016). Na última semana de 2016, a Associação dos Embaixadores de Turismo do Rio de Janeiro (Abemtur-RJ) realizou uma pesquisa com mil turistas estrangeiros em oito bairros cariocas que apontou que essa área recebeu na semana da pesquisa mais visitantes do que as praias, até então um dos principais atrativos do Rio, ficando atrás somente do Corcovado e do Pão de Açúcar (ABEMTUR, 2016).

Ao ser questionado sobre as estratégias de city marketing, o presidente entrevistado da APO afirmou que, embora estivesse prevista como ação estratégica nos Planos e, apesar de algumas campanhas, o Rio não se atentou à promoção da cidade renovada como deveria:

A prefeitura do Rio hoje está focada em entregar os jogos, então há um volume de iniciativas grande em relação à infraestrutura para os jogos e para o turismo. Estamos modernizando a sinalização turística e ampliando a oferta de hotéis. Eu acho que pro Rio hoje é mais importante a entrega dos jogos e, num segundo momento, é a promoção dessa nova percepção de um novo Rio. Imagino que mais próximo dos jogos a Prefeitura vai lançar uma campanha pra despertar a percepção em relação ao novo Rio, assim como a Embratur também, em nível nacional.

Contudo, em julho de 2016, o Palácio do Planalto decidiu que não mais haveria campanhas para divulgar o Brasil no exterior justificando que o cronograma fora prejudicado pela troca de presidentes na Embratur somada à falta de verba e às incertezas políticas causadas pelo afastamento da então presidente Dilma Rousseff em maio do mesmo ano (AMADO, 2016), não efetivando tais iniciativas estratégicas previstas nos Planos.

Sendo um dos principais objetivos dos Planos Estratégicos o de aproveitar os Jogos para atrair fluxo de turistas e capital estrangeiro, uma ação para concretizar tal meta foi a ampliação do número de leitos na cidade e a reforma hoteleira, como prevê o quarto pilar da iniciativa "Rio Capital do Turismo". Com o enfoque no turista estrangeiro, o Rio dispendeu investimentos nas zonas já elitizadas e turísticas, como em Copacabana, na zona sul, e também na zona oeste, na Barra da Tijuca. De acordo com o presidente da APO entrevistado, a hotelaria no Rio sofria pressão, pois os hotéis eram caros e estavam com a estrutura obsoleta e baixa ocupação. A cidade precisava tornar-se mais competitiva internacionalmente e isso passava pela renovação da hotelaria.

O presidente da Empresa Olímpica Municipal (EOM)[7] afirmou em entrevista que a prefeitura investiu muito em termos de legislação e incentivo à ampliação da rede hoteleira, que envolveu desde a construção e reforma de hotéis à transformação de uso de motéis para hotéis, mas que pouco se pensou em estratégias que incluíssem a população como parte desses negócios. Embora o turismo também se consolide por meio 
do Airbnb, dos hostels e de hospedagens nas comunidades, os Planos não incluíram a população local nas discussões acerca do desenvolvimento desse setor, ficando os lucros concentrados nas mãos de poucos agentes privados (FERNANDES, 2017).

O presidente da EOM também destacou em entrevista que o investimento da prefeitura no turismo ultrapassou o campo da infraestrutura e deixou um legado intangível no que diz respeito à capacitação profissional para a área, pois promoveu alguns cursos de qualificação no atendimento em parceria com os hotéis. A prefeitura adotou o ensino de inglês da 1a a 9a série, meta proposta no Plano Estratégico, a fim de transformar esses alunos em profissionais capacitados para trabalharem no setor turístico, o que demonstra a intencionalidade de promoção dessa atividade.

Ainda de acordo com o presidente da EOM, a rede hoteleira foi ampliada de 29 mil para 66 mil leitos para acompanhar o desejado aumento da demanda impulsionada pelos megaeventos. Contudo, como a cidade não desenvolveu estratégias sólidas para assegurar o fluxo esperado, este se concretizou apenas nos períodos da Copa e dos Jogos, mostrando que os atrativos eram os megaeventos e não a cidade em si, o que pode fazer com que esses investimentos tornem-se subutilizados, de alto custo e desnecessários.

A fala do presidente da Embratur no período dos Jogos, Vinícius Lummertz, evidenciou a estratégia de inserir o Rio no mercado global ao compará-lo a Barcelona, no que tange ao fluxo turístico: "a cidade de Barcelona recebia 1,8 milhão de turistas por ano e, após os Jogos, chegou à marca atual de 8 milhões. Esperamos que o Rio de Janeiro cresça nessa proporção" (MINISTÉRIO DO TURISMO, 2016). Todavia, os gestores ignoram o fato de que, atualmente, Barcelona vive um colapso de seu "modelo" de gestão turística. A mentalidade brasileira ainda valoriza os dados quantitativos sem relativizar os danos, os conflitos e as contradições que tal atividade, planejada por e para o benefício de empresários e investidores, pode gerar para uma população. Após mais de 20 anos tornar-se um "modelo", os moradores de Barcelona travam uma luta diária contra as políticas de desenvolvimento massivo do turismo (FERNANDES, 2017).

Contudo, o modo como o turismo vem sendo desenvolvido nas áreas que sofreram renovações no Rio, embora esteja longe da realidade de Barcelona, já impulsionou a especulação imobiliária, o aumento do custo de vida e as desigualdades, a exemplo do que aconteceu na região portuária, que levou ao enobrecimento e ao uso turístico dessa área graças aos equipamentos culturais e de lazer.

De acordo com o guia de turismo e morador da região portuária entrevistado, houve muitas expulsões e remoções de população do local: "as obras aqui na região implicaram em remoções. [...] ficou cada vez mais caro morar no Centro. Nenhuma dessas intervenções realizadas considerou o morador. Isso desde o Pan [2007]".

Os aluguéis e a compra e venda de imóveis tiveram os valores inflacionados (GIANELLA, 2015). O morador que não sofreu a remoção forçada, sofreu uma remoção simbólica, pois não tem mais condições de se manter no local devido ao aumento do custo de vida. Em julho de 2016, um mês antes dos Jogos, o Rio já figurava como a décima cidade mais cara do mundo, em um estudo que considerou gastos com hotel, refeições, atrações e táxi. As cidades que encabeçam essa lista são Nova York (EUA), Tóquio (Japão) e Londres (Inglaterra) (MACHADO, 2016). Considerando que as três primeiras cidades da lista são dotadas de relevante infraestrutura básica e turística, além de bons índices de segurança pública, o Rio oferece uma infraestrutura precária e com alto custo, o que impacta a sua população em primeiro lugar.

Tais processos mostram que a sua gestão estratégica esteve focada em ações para potencializar o turismo, ignorando os efeitos perversos dessa atividade. Os Planos Estratégicos não discutiram meios para lidar com o maior fluxo desejado de turistas e tampouco discutiram como lidar com as possíveis desigualdades geradas pelas novas demandas. Ignoraram os efeitos nefastos que a questão da especulação imobiliária alimenta e focou-se somente em iniciativas de competitividade e não nos efeitos indesejados que o turismo massificado e a ação dos agentes hegemônicos poderiam trazer.

Ainda é importante destacar que a gestão pública de turismo do Rio é bastante fragilizada e sofreu com alterações em sua estrutura. Isso se deve ao fato de o cenário político-econômico nada favorável decorrente de 
sua má administração pública e dos escândalos de corrupção que todo o estado vem enfrentando: em junho de 2016 foi decretado estado de calamidade econômica a fim de que a gestão pública pudesse tomar medidas excepcionais para garantir a realização dos Jogos, e os servidores públicos ficaram com os salários atrasados e ainda há muitas dívidas orçamentárias (CALEIRO, 2016).

Até 2016, a organização turística contava com a Empresa de Turismo do Município do Rio de Janeiro (Riotur), criada na década de 1960, e a Secretaria de Estado de Turismo (Setur), criada em 2010. Em dezembro de 2016, o atual prefeito Marcelo Crivella anunciou a extinção da Secretaria e informou que as decisões acerca da atividade serão de responsabilidade da Riotur e de um Conselho ligado diretamente ao seu gabinete, formado por empresários como José Bonifácio (Boni), da Rede Globo de Televisão, e Roberto Medina, idealizador de eventos como o Rock in Rio (MENEZES, 2016), mostrando a continuidade das coalizações hegemônicas entre o poder público e o privado na gestão da cidade.

Não obstante, outras imagens obtiveram alcance internacional, mas em vez de promoverem a cidade renovada, promoveram os conflitos e as desigualdades do Rio Olímpico, a exemplo da Figura 5, que mostra a polícia e os bombeiros cariocas recebendo os turistas e atletas olímpicos, em junho de 2016, com faixas no aeroporto internacional em protesto contra os seus salários atrasados.

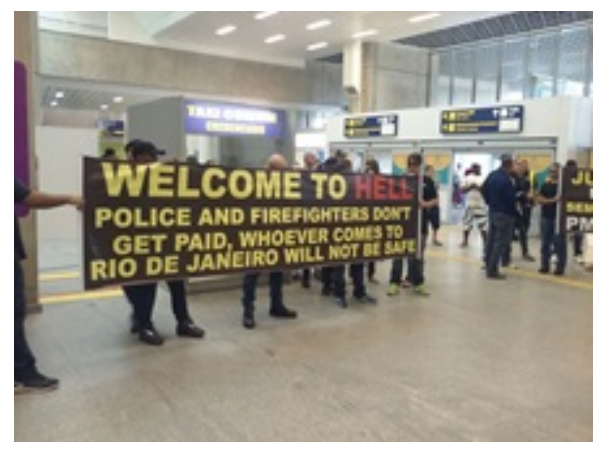

FIGURA 5

"Bem-vindos ao inferno"

Ramalho, 2016.

Em face do que foi analisado, a gestão focada no empreendedorismo urbano materializa grandes projetos em prol de investidores e turistas, tornando a cidade um objeto de consumo em vez de sujeito:

Os espaços públicos são capturados pela espetacularização e transformados em cenários midiáticos, homogêneos, marcas registradas da cidade. Como alvos de "revitalização" têm como referência os espaços privados: controlados, domesticados e seguros. Os projetos do Porto Maravilha, do novo Maracanã e do Parque Olímpico são exemplos emblemáticos dessa espetacularização homogeneizadora (SÁNCHEZ; GUTERMAN; LAIBER, 2015, p. 5-6).

Em março de 2016 a prefeitura lançou seu mais recente Plano Estratégico (2017-2020) no Museu do Amanhã, símbolo máximo da nova imagem da cidade. O novo Plano contempla 59 iniciativas estratégicas e apresenta 70 aspirações para o município até 2065, ano que o Rio completará 500 anos. Uma das aspirações é o Rio tornar-se a cidade com maior fluxo de turistas internacionais da América Latina (PREFEITURA DA CIDADE DO RIO DE JANEIRO, 2016), o que comprova que a orientação para o posicionamento competitivo continuará.

\section{CONSIDERAÇÕES FINAIS}

Desde a década de 1990 a cidade do Rio de Janeiro tem se tornado palco de políticas estratégicas que vêm promovendo uma renovação urbana em seu espaço por meio da realização de megaeventos esportivos, bem como a divulgação de sua imagem para reforçá-la no mercado turístico mundial. Foi a partir desse cenário que as discussões aqui apresentadas foram conduzidas, no intuito de analisar de que forma o Rio de Janeiro 
guiou a sua governança pública a partir de Planos Estratégicos, sobretudo no que tange às ações previstas para o fomento do turismo e para a promoção da sua imagem.

A consolidação dos Planos Estratégicos enfraqueceu o Plano Diretor da cidade e, nesse caso, as tomadas de decisões se centraram cada vez mais nas coalizões público-privadas que, em sua maioria, deixaram à margem os interesses da população. Prova disso é que nenhuma iniciativa estratégica mencionou o desenvolvimento qualitativo do turismo participativo, com a população envolvida, e de forma sustentável; somente focou no aumento do fluxo de turistas.

Constatou-se que os investimentos para os megaeventos foram concentrados somente em algumas áreas da cidade e atenderam a uma parcela minoritária, como promotores imobiliários, empresários do trade turístico e poder público, em um processo gerador de desigualdades. A remoção da população local da região portuária, por exemplo, evidenciou que tais políticas visaram a valorização e a financeirização do solo em detrimento do bem-estar social. Tal processo pôde ser percebido pela espetacularização e elitização dos espaços públicos a partir da instalação de equipamentos culturais e de lazer, muitas vezes desconexos da realidade do morador local, em um processo claro de gentrificação.

Assim, pode-se afirmar que as iniciativas estratégicas analisadas para o desenvolvimento do turismo são consideradas oportunidades somente para a classe hegemônica, pois, no caso da renovação portuária, contribuíram para reforçar desigualdades já existentes, afinal, foram altos os investimentos para uma minoria ante a precarização dos serviços para a população.

Sobre isso, Boykoff (PUFF, 2016, n. p.) explica que nenhuma Olimpíada recente serviu para o bem coletivo, e esse processo ficou evidente na experiência carioca, pois "muito desse dinheiro público acabou servindo para proporcionar vantagens aos segmentos mais ricos da população carioca, as elites econômica e políticas". Além disso, o legado não foi cumprido, pois não houve melhoria no saneamento básico, tratamento de esgoto e tampouco ocorreu a despoluição da Baía de Guanabara, prevista como uma das metas estratégicas do Plano.

As ações estratégicas que resultam em projetos de intervenção urbana deveriam ser aproveitadas como uma verdadeira oportunidade de melhorar a qualidade dos espaços públicos das cidades. $\mathrm{O}$ turismo, quando desenvolvido dentro de bases sustentáveis que consideram o espaço, a sua população local, bem como o meio ambiente no qual está inserido, é uma atividade que pode proporcionar a troca entre diferentes culturas, o respeito às alteridades e os benefícios econômicos para a localidade onde se encontra.

Os projetos devem ser analisados levando em consideração o desenho de futuras estratégias a médio e longo prazos abarcando todos os agentes. Para isso, é fundamental considerar formas de gestão que sejam compartilhadas, participativas e descentralizadas, onde a população tenha espaço para opinar e debater acerca de seus desejos e de suas necessidades, podendo contar com o apoio de empresas e outras forças de mercado que cooperem com investimentos que atendam a essas demandas e, sobretudo, com o poder público na elaboração e na garantia de efetivação de políticas públicas.

Nesse contexto, o desafio maior do planejamento e da gestão turística das cidades-sede de megaeventos é buscar o equilíbrio entre as oportunidades de investimentos e o legado para a população, sem fazer com que a cidade se torne objeto de luxo acessível somente para quem pode consumi-la.

\section{REFERÊNCIAS}

AMADO, G. Brasil não terá mais campanha para atrair turistas durante Olimpíada. In: O Globo. 10 de julho, 2016.

ASSOCIAÇÃO DOS EMBAIXADORES DE TURISMO DO RIO DE JANEIRO. 2016. Disponível em: https://www.facebook.com/Associacao-Dos-embaixadores-de-turismo-do-Rio-de-JaneiroAbemtur-RJ-827314160666263. Acesso em: jan. 2017.

BARCELONA TURISME. Estadístiques de turisme a Barcelona i comarques. Ayuntamiento de Barcelona, 2015. BORJA, J.; FORN, M. Políticas da Europa e dos Estados para as cidades. Espaço e Debates, ano XVI, n. 39, 1996. 
BRASIL. Ministério do Turismo. Relatório Eventos Internacionais no Brasil (2003-2009). Brasília, DF: Ministério do Turismo, 2011.

BRASIL. Ministério do Turismo. Índice de Competitividade do Turismo Nacional: relatório Brasil. Brasília, DF: Ministério do Turismo, 2015.

BRASIL. Ministério do Turismo. Turistas aprovam a Olimpíada e querem voltar ao Brasil. 19 ago. 2016. Disponível em: http://www.turismo.gov.br/ultimasnoticias-7041-turistas-aprovam-as-olimpiadas-e-queremvoltar-ao-brasil.htlm. Acesso em: set. 2016.

BRITO, C. Após quatro meses, Parque Olímpico no Rio tem sinais de abandono. Rio de Janeiro, fev. 2017. Disponível em: http:// https://g1.globo.com/rio-de-janeiro/noticia/apos-quatro-meses-parque-olimpico-norio-tem-sinais-de-abandono.ghtml. Acesso em: jul. 2017.

CALEIRO, J. P. Rio de Janeiro e Minas Gerais, os estados ricos e falidos. Revista Exame.com. 2016. Disponível em: http://exame.abril.com.br/economia/rio-de-janeiro-e-minas-gerais-se-ricos-por-que-falidos/. Acesso em: jan. 2017.

CARLOS, C. A. S. L. O patrimônio cultural na cidade dos grandes eventos e oportunidades - reflexões sobre o patrimônio cultural frente ao contexto político-administrativo da cidade do Rio de Janeiro no século XXI. Cadernos do Proarq. n. 21. Rio de Janeiro: Universidade Federal do Rio de Janeiro, 2013. p. 29-45.

FERNANDES, A. M. V. Patrimônio Cultural, Turismo e a Renovação das Cidades: aproximações e dissonâncias entre Barcelona e Rio de Janeiro. Tese (Doutorado). Programa de Pós-graduação em Geografia da Universidade Estadual de Campinas (Unicamp). Campinas, 2017.

FISCHER, T.; GUANAIS, F. C. Entre planos, projetos e estratégias: o caso Rio Sempre Rio. Organizações e Sociedade. v. 6, n. 14, janeiro/abril. Salvador, 1999.

GIANNELLA, L. C. Revirando o "Porto Maravilha": luta pelo espaço e contradições urbanas na zona portuária do Rio de Janeiro. Tese (Doutorado). Programa de Pós-graduação em Geografia da Universidade Federal Fluminense (UFF). Niterói, 2015.

HARVEY, D. Do gerenciamento ao empresariamento: a transformação da administração urbana no capitalismo tardio. Espaço e Debates, v. 39, n. 16, p. 48-64, 1996.

MACHADO, R. Rio está entre as cidades mais caras do mundo. In: Panrotas. 19 de julho, 2016. Disponível em: http://www.panrotas.com.br/noticia-turismo/destinos/2016/07/rio-esta-entre-cidades-maiscaras-do-mundo.127639.html. Acesso em: ago. 2016.

MARTINS, F. No Rio, Paes distribui nas escolas "Banco Imobiliário" que exalta suas obras. In: UOL. Rio de Janeiro, 2013. Disponível em: http://educacao.uol.com.br/noticias/2013/02/22/prefeitura-do-rio-vai-distribuir-nasescolas-banco-imobiliario-que-exalta-obras-de-paes.htm. Acesso em: nov. 2016.

OLIVEIRA, M. P. Projeto Rio Cidade: intervenção urbanística, planejamento urbano e restrição à cidadania na cidade do Rio de Janeiro. Diez años de cambio en el Mundo, en la Geografía y en las Ciencias Sociales, 1999-2008. Scripta Nova. Revista Electronica de Geografía y Ciencias Sociales. Barcelona: Universidad de Barcelona, 1 de agosto de 2008, vol. XII, n. 270 (117). Disponível em: http://www.ub.es/geocritic/sn/sn-270-117.htm.

PIRES, H. F. Planejamento e intervenções urbanísticas no Rio de Janeiro: a utopia do Plano Estratégico e sua inspiração catalã. Biblio 3W. Revista Bibliográfica de Geografía y Ciencias Sociales. Barcelona: Universidad de Barcelona, 5 de noviembre de 2010, v. XV, n. 895 (13). Disponível em: http://www.ub.es/geocritic/ b3w-895-13.htm.

PREFEITURA DA CIDADE DO RIO DE JANEIRO. Plano Estratégico da Prefeitura do Rio de Janeiro: o Rio mais integrado e competitivo (2009 - 2012). Rio de Janeiro, 2009. Disponível em: http:// www.conselhodacidade.com.br/v3/pdf/planejamento_estrategico_site.pdf. Acesso em: 28 maio 2016.

PREFEITURA DA CIDADE DO RIO DE JANEIRO. Plano Estratégico da Prefeitura do Rio de Janeiro: o Rio mais integrado e competitivo - Pós-2016 (2013 - 2016). Rio de Janeiro, 2013. Disponível em: http:// www.conselhodacidade.com.br/v3/pdf/planejamento_estrategico_13-16.pdf. Acesso em: 14 jul. 2016. 
PREFEITURA DA CIDADE DO RIO DE JANEIRO. Plano Estratégico da Prefeitura do Rio de Janeiro - 2017-2020. Rio de Janeiro, 2016. Disponível em: http://www.conselhodacidade.com.br/v3/pdf/ planejamento_estrategico_17-20.pdf. Acesso em: 29 out. 2016.

PREFEITURA DA CIDADE DO RIO DE JANEIRO. Concurso Rio em Cartaz. Disponível em: http:// www.rio.rj.gov.br/web/irph/rioemcartaz . Acesso em: jul. 2016.

PREFEITURA DA CIDADE DO RIO DE JANEIRO. Visit.rio Magazine. Rio de Janeiro. n. 1, janeiro de 2016.

PUFF, J. Rio 2016 escancara crise do modelo dos Jogos Olímpicos "como nunca antes". Entrevista do professor pesquisador BOYKOFF, J. à BBC do Rio de Janeiro. In: BBB Brasil. Rio de Janeiro. 12 julho, 2016. Disponível em: http://www.bbc.com/portuguese/brasil-36770268. Acesso em: set. 2016.

RAMALHO, G. Policiais e bombeiros fazem manifestação dentro do Galeão. In: O Globo. 04/06/2016. Disponível em: < http://oglobo.globo.com/rio/policiais-bombeiros-fazem-manifestacao-dentro-do-galeao-19590123>. Acesso em: jun. 2016.

SANCHÉZ, F.; GUTERMAN, B.; LAIBER, P. Disputas simbólicas na cidade maravilhosa: atores, instrumentos e gramáticas territoriais. XVI ENANPUR: ESPAÇO, PLANEJAMENTO E INSURGÊNCIAS. Belo Horizonte, maio de 2015. Anais... Belo Horizonte, 2015.

VAINER, C. Pátria, empresa e mercadoria: notas sobre a estratégia discursiva do Planejamento Estratégico Urbano. In: ARANTES, O.; MARICATO, E.; VAINER, C. A cidade do pensamento único: desmanchando consensos. 3. ed. Petrópolis, RJ: Vozes, 2002. p. 75-104.

VIEIRA, R. Mtur revela os destinos mais postados no Instagram. Panrotas. 2016. Disponível em: http://www.panrotas.com.br/noticia-turismo/destinos/2016/12/mtur-revela-os-destinos-mais-postadosno-instagram-fotos_142977.html. Acesso em: jan. 2017.

VIGNATI, F. Gestão de destinos turísticos: como atrair pessoas para polos, cidades e países. Rio de Janeiro: Ed. Senac Rio, 2008.

\section{Notas}

[1] César Maia foi prefeito da cidade do Rio de Janeiro de 1993 a 1997; de 2001 a 2005 e de 2005 a 2009.

[2] Consórcio Interfederativo Tripartite da Administração Pública Brasileira, criado por meio da Lei 12.396/2011, com o objetivo de coordenar a participação da União, do Estado e do Município do Rio de Janeiro na organização, realização e gestão dos Jogos 2016. Denominado Autoridade Pública Olímpica (APO), foi desmontado após a finalização dos Jogos Paralímpicos, em setembro de 2016. Dados coletados em entrevista concedida em pesquisa de campo realizada na sede da APO, maio, 2016.

[3] As análises referentes aos demais projetos de renovação urbana, bem como de seus impactos, podem ser consultadas na tese e em outros artigos do autor.

[4] Centros de lazer e convivência equipados com telóes, shows e diversos tipos de entretenimento. Esses espaços permitiram que o público também acompanhasse as competições olímpicas pelos telóes.

[5] Entrevista concedida em pesquisa de campo realizada na região portuária, janeiro, 2016.

[6] O Museu do Amanhã tem o Grupo Globo como parceiro Estratégico, o Banco Santander como patrocinador principal e a Shell como mantenedora. Fonte: Museu do Amanhã. Disponível em: . Acesso em: novembro de 2017.

[7] Dados coletados em entrevista concedida em pesquisa de campo. Maio, 2016.

\section{BY}

\section{INFORMAÇÃO ADICIONAL}

Nota:: O presente artigo é fruto de pesquisas realizadas em tese de doutorado defendida no Programa de PósGraduação em Geografia da Universidade Estadual de Campinas (UNICAMP), sob orientação da professora Dra. Maria Tereza Duarte Paes, com estágio de 6 meses na Universitat de Barcelona, Espanha, como bolsista CAPES-PDSE. 